\title{
Structural Determinants of Barium Permeation and Rectification in Non-NMDA Glutamate Receptor Channels
}

\author{
Raymond Dingledine, ${ }^{1,2}$ Richard I. Hume, ${ }^{1,3}$ and Stephen F. Heinemann ${ }^{1}$ \\ ${ }^{1}$ Molecular Neurobiology Laboratory, Salk Institute, La Jolla, California 92037, 2Department of Pharmacology, University of \\ North Carolina, Chapel Hill, North Carolina 27599, and ${ }^{3}$ Department of Biology, University of Michigan, Ann Arbor, \\ Michigan 48109
}

\begin{abstract}
A single site in recombinant glutamate receptor channels of the GluR1-GluR4 family has been previously identified as a key regulator of ion permeation. The natural amino acid at this position (arginine in GluR2 but glutamine in GluR1, GluR3, and GluR4) determines both the ability to pass outward current and the divalent cation permeability of kainate-activated receptor channels. By mutagenesis of GluR6, we demonstrated that the same site also controls the ability to pass outward current in another non-NMDA receptor family. Additional mutations at and near this site in GluR3 indicated that the position of the arginine is critical to function, that the ability to pass outward current is not necessarily linked to low barium permeability, and that the size as well as the charge of the side chain at this position influences barium permeation. These results provide evidence that this site forms part of the selectivity filter of glutamate receptor channels.
\end{abstract}

Calcium permeation through glutamate receptors of the NMDA type plays key roles in such diverse phenomena as long-term potentiation, excitotoxicity, and epileptic discharges. Although the calcium permeability of non-NMDA glutamate receptor channels is generally thought to be very low (e.g., Mayer and Westbrook, 1987), recent evidence demonstrates that nonNMDA receptors in certain neurons and type 2 astrocytes exhibit considerable permeation to calcium or other divalent cations when activated by kainate (Murphy et al., 1987; Glaum et al., 1990; Iino et al., 1990; Gilbertson et al., 1991; Pruss et al., 1991).

Studies with recombinant non-NMDA glutamate receptors of the GluR 1-GluR4 family showed that multiple subunits coassemble to form glutamate receptors with different functional properties (Boulter et al., 1990; Keinanen et al., 1990; Nakanishi et al., 1990; Sakimura et al., 1990). The presence or absence of the GluR2 subunit determines the ability to pass outward currents at moderately positive $(<+50 \mathrm{mV})$ potentials as well as the degree of calcium permeability in this family (Hollmann et

\footnotetext{
Received March 27, 1992; revised May 19, 1992; accepted May 27, 1992.

We thank Jim Boulter, Jan Egebjerg, Scott Rogers, and the other members of Molecular Neurobiology Lab for help and advice throughout these studies. This work was supported by U.S. Public Health Service (USPHS) Grants NS27452 and NS17771, the Bristol-Myers Squibb Co., and the Klingenstein Foundation (R.D.); USPHS Grants NS25782 and NS21043 (R.I.H.); USPHS Grant NS28709 (S.F.H.); and a Howard Hughes grant to C. F. Stevens.

Correspondence should be addressed to Raymond Dingledine, Department of Pharmacology, Emory University School of Medicine, Atlanta, GA 30322.

Copyright (C) 1992 Society for Neuroscience $0270-6474 / 92 / 124080-08 \$ 05.00 / 0$
}

al., 1991). In contrast to voltage-dependent calcium channels, calcium-permeable glutamate receptor channels are also permeable to a wide range of divalent cations including magnesium (Hollmann et al., 1991; Burnashev et al., 1992) and probably cobalt (Pruss et al., 1991).

Site-directed mutagenesis has been used to identify a single position that appears to determine certain ion permeation propertics of recombinant reccptors in the GluR1-GluR4 family. When a glutamine resides in this position, as in GluR1 and GluR3, the resulting receptors have high barium permeability (Hume et al., 1991) and an inwardly rectifying $I-V$ relation (Hume et al., 1991; Verdoorn et al., 1991). When this site contains an arginine, as occurs naturally in GluR2, homomeric receptors carry little current by themselves but can combine with GluR1 or GluR3 to form receptors with low barium permeability (Hume et al., 1991) and outward rectification (Hume et al., 1991; Verdoorn et al., 1991). This critical position in the GluR1-GluR4 sequences will be referred to as the $Q / R$ site. The amino acid sequence of this putative transmembrane region is otherwise identical in rat GluR1-GluR4. The functional importance of this amino acid residue is highlighted by the finding that the gene for GluR2 contains a glutamine codon rather than the arginine codon found in the RNA, implying that posttranscriptional cditing achicves the mature RNA species (Sommer et al., 1991). If this RNA editing process were itself regulated, neurons would have an additional means to modify the degree of calcium permeation through glutamate-activated AMPA receptor channels.

A major goal of this study was to explore in more detail the role the $Q / R$ site plays in rectification and divalent ion permeability of glutamate receptor channels. To this end, we made a series of additional mutations at and near this site. One important outcome of these experiments is that they provide evidence that this domain contributes to the selectivity filter of the channel.

The members of the first family of non-NMDA glutamate receptors to be cloned (GluR1-GluR4) respond to both AMPA and kainate, whereas the second family of non-NMDA receptors, represented by GluR5-GluR7, has a pharmacological profile expccted of kainatc receptors (Bettler et al., 1990, 1992; Egebjerg et al., 1991). Members of this family also exist with either glutamine or arginine in the critical position (Sommer et al., 1991). A second issue addressed here is whether the arginine/ glutamine switch in the GluR5-GluR7 family has the same functional consequences as it does in the GluR1-GluR4 family. Finally, the first NMDA receptor subunit cloned contains a 
neutral asparagine in the homologous position (Moriyoshi et al., 1991). In one GluR 3 mutant, we inserted an asparagine into the $Q / R$ site to examine whether there may be similarities in the conduction pathways of all classes of glutamate activated channels.

\section{Materials and Methods}

Construction of mutants. The parent clones (GluR1, GluR2, GluR3, GluR6) and all recombinant products were in the plasmid Bluescript $\mathrm{SK}^{-}$. The nomenclature used in this article to refer to the subunits is that of Boulter et al. (1990), and the numbering system used counts from the presumptive initiator methionine. An alternative nomenclature uses GluRA-GluRC rather than GluR1-GluR3 to refer to these subunits (Keinanen et al. 1990), and numbers the amino acids from the amino terminus of the putative mature proteins rather than from the presumptive initiator methionine.

Site-directed mutations were made with the Amersham oligonucleotide-directed in vitro mutagenesis system, version 2 . Single-stranded DNA templates were rescued from the double-stranded plasmids with helper phage VCSM13 (Vieira and Messing, 1987). The primers for mutagenesis incorporated two types of changes. One caused the desired change in amino acid sequence, while the second created a silent restriction site that was used to screen transformants for the presence of the mutant. Escherichia coli strain NM522 was transformed with the recombinant plasmids, and the production of mutants was verified by restriction site analysis and then sequencing through the mutant region.

Recording methods. Xenopus oocytes (stage V-VI) were injected with 2-25 ng of RNA transcribed in vitro by T3 RNA polymerase as described (Hollmann et al., 1989). Combinations of GluR1 and a second subunit were coinjected at a ratio of 1 to 5 to reduce the probability of the formation of homomeric GluR 1 receptors. Two-electrode voltage-clamp recordings were made $2-15 \mathrm{~d}$ after injection. For routine recording, oocytes were bathed in a solution containing $90 \mathrm{mM} \mathrm{NaCl}, 1 \mathrm{mM} \mathrm{KCl}$, 1.7-1.8 $\mathrm{mM} \mathrm{MgCl}_{2}, 0.1 \mathrm{mM} \mathrm{CaCl}_{2}$, and $15 \mathrm{mM}$ HEPES, pH 7.6. The low $\mathrm{Ca}^{2+}$ concentration minimized the secondary activation of the $\mathrm{Ca}^{2+}$ dependent Cl currents (Barish, 1983; Miledi and Parker, 1984). Kainate was applied by bath perfusion. In most experiments $300 \mu \mathrm{M}$ kainate was used to activate glutamate receptors, but for studies on GluR6, 10 $\mu \mathrm{M}$ kainate was usually used.

$I-V$ relations were obtained by applying $2 \mathrm{sec}$ voltage ramps (typically from -100 to $+50 \mathrm{mV}$ ) in the presence and absence of kainate, and then subtracting the resting $I-V$ curve from that in the presence of kainate. To summarize the degree of rectification in the $I-V$ relation of each cell, the ratio of the slope conductance at a positive and a negative potential was calculated. Slope conductance was calculated by measuring the current $5 \mathrm{mV}$ positive and negative to the indicated potentials and dividing the difference by $10 \mathrm{mV}$.

The relative permeability to $\mathrm{Ba}$ and $\mathrm{Na}$ was assessed by measuring the shift in reversal potential when $90 \mathrm{mM} \mathrm{NaCl}$ was replaced with 60 $\mathrm{mM} \mathrm{BaCl}{ }_{2}$ (Hume et al., 1991). Several complications ensued from this substitution. First, there was a junction potential difference between the two solutions, which ranged from 5 to $15 \mathrm{mV}$. A correction for this junction potential has been included in the reported reversal potential values. Second, for combinations of subunits with strong inward rectification, there was often no clear reversal from inward to outward current. Rather, the current asymptotically approached zero and remained there at more positive potentials. In these cases, we considered the reversal potential to be the zero current potential, defined as the least negative potential at which there was still detectable inward current (about $-1 \mathrm{nA}$ ). Finally, the entry of divalent cations through open channcls often sccondarily activated a calcium-dependent chloride channel. Although we were not able to suppress this current fully in high-calcium solutions, the qualitative effects of high- $\mathrm{Ba}^{2+}$ and high$\mathrm{Ca}^{2+}$ solutions on $I-V^{r}$ relations were the same (Hume et al., 1991). The use of $\mathrm{Ba}^{2+}$ rather than $\mathrm{Ca}^{2+}$ diminished but did not usually eliminate this current (cf. Boton et al., 1989). The calcium-dependent chloride current was suppressed by keeping the kainate application brief and, in most experiments, by including $0.4 \mathrm{M}$ EGTA [ethylene glycol bis $(\beta$ aminoethyl)ether- $N, N, N^{\prime}, N^{\prime}$-tetra-acetic acid) as well as $3 \mathrm{M} \mathrm{KCl}$ in the recording and current pipettes. In other experiments, EGTA was omitted from the intracellular solution and all extracellular chloride was replaced by methanesulfonate (Dascal et al., 1986). The chloride current was suppressed by either of these treatments as long as the kainate application was brief. For example, for GluR $1+$ GluR 3 receptors, the kainate reversal potential was more negative in the methanesulfonate solution without intracellular EGTA $(-23 \pm 6.5 \mathrm{mV} ; n=5)$ than in the standard chloride solution with intracellular EGTA $(-7 \pm 3 \mathrm{mV})$, indicative of very low chloride permeability. The shift in kainate reversal potential upon replacing $\mathrm{Na}^{+}$with $\mathrm{Ba}^{2+}$ was the same in both conditions $(+23$ and $+21 \mathrm{mV}$, respectively), however, so data from the two conditions have been pooled.

In contrast to the records shown in this article, long applications of kainate $(>15 \mathrm{sec})$ often produced substantial outward currents in oocytes injected with any of the combinations of subunits that had strongly inwardly rectifying $I-V$ relations in low $\mathrm{Ca}^{2+}$, due to the secondary activation of the chloride current.

The relative permeability of $\mathrm{Ba}$ and $\mathrm{Na}$ was calculated from the Goldman-Hodgkin-Katz equation modified to include divalent cations. To make these calculations, several simplifying assumptions were made. It was assumed that anion permeability was negligible and that all monovalent cations were equally permeable. These first two assumptions were verified experimentally with some, but not all, combinations of subunits. In all cases studied, substitution of an equimolar concentration of the large anion, methanesulfonate, for chloride caused no shift in reversal potential, and substitution of $90 \mathrm{mM} \mathrm{KCl}$ for the normal $90 \mathrm{mM} \mathrm{NaCl}$ did not cause a change of more than $5 \mathrm{mV}$ in the reversal potential. In addition, a value of $150 \mathrm{mM}$ was assumed for the intracellular monovalent cation concentration, since this value was necessary to yield the measured reversal potentials in the standard solution. Calculations were made with and without compensation for the negative surface potential (Lewis, 1979; Ascher and Nowak, 1988). The magnitude of this effect depends critically on the number and distribution of charges around the extracellular mouth of the channel, information not yet available. A surface charge equivalent to $-20 \mathrm{mV}$ at the channel would reduce the estimated permeability ratio of GluR $1+$ GluR 3 receptors from about 3 to about 2 .

\section{Results}

\section{Glutamine/arginine switch controls rectification in GluR6}

The first GluR6 clone to be isolated had an arginine in the site homologous to the $Q / R$ site of GluR $1-G l u R 4$. When expressed in oocytes, this clone produced kainate-evoked currents with an outwardly rectifying $I-V$ relation (Egebjerg et al., 1991). Subsequently, naturally occurring GluR6 sequences were identified with glutamine in this position but otherwise identical surrounding sequence (Sommer et al., 1991), as indicated in Figure $1 \mathrm{~A}$. We used site-directed mutagenesis to convert the arginine of GluR6 (Egebjerg et al., 1991) to a glutamine. Homomeric GluR6(R621) or GluR6(Q621) receptors expressed in Xenopus oocytes both carried inward current in response to kainate. As was the case for GluR6(R621) (Egebjerg et al., 1991), responses of GluR6(Q621) were potentiated more than 50-fold by application of $10 \mu \mathrm{M}$ concanavalin A (Fig. $1 B$ ), a compound known to reduce desensitization. The presence of a glutamine at the $\mathrm{Q} / \mathrm{R}$ site caused the kainate $I-V$ relation to be strongly inwardly rectifying (rectification index, $0.04 \pm 0.05 ; n=15$ ) rather than outwardly rectifying as seen when GluR6 contains arginine (Fig. $1 C$; rectification index, $3.2 \pm 0.39 ; n=9$; see also Egebjerg et al., 1991). These results demonstrate that the $Q / R$ site is functionally important in the GluR5-GluR7 family of non-NMDA receptors as well as in the GluR1-GluR4 family.

\section{Rationale for construction of additional GluR3 mutants}

From previous results, it is unclear whether the size or charge of the residue in the $\mathrm{Q} / \mathrm{R}$ site controls permeation properties (Hume et al., 1991; Verdoorn et al., 1991; Burnashev et al., 1992). The presence of an arginine at the $Q / R$ site might alter channel properties because the arginine interacts in a specific manner with other residues; in this case, the size and position of the arginine might be critical. Alternatively, any positive charge in the vicinity of the $Q / R$ site may suffice to switch the GluR3 phenotype. These ideas were tested in three ways. One 
A. GluR6 $\quad$...ENNFTLLNSFWFGVGALM ${ }_{R}^{Q G S E} \ldots$
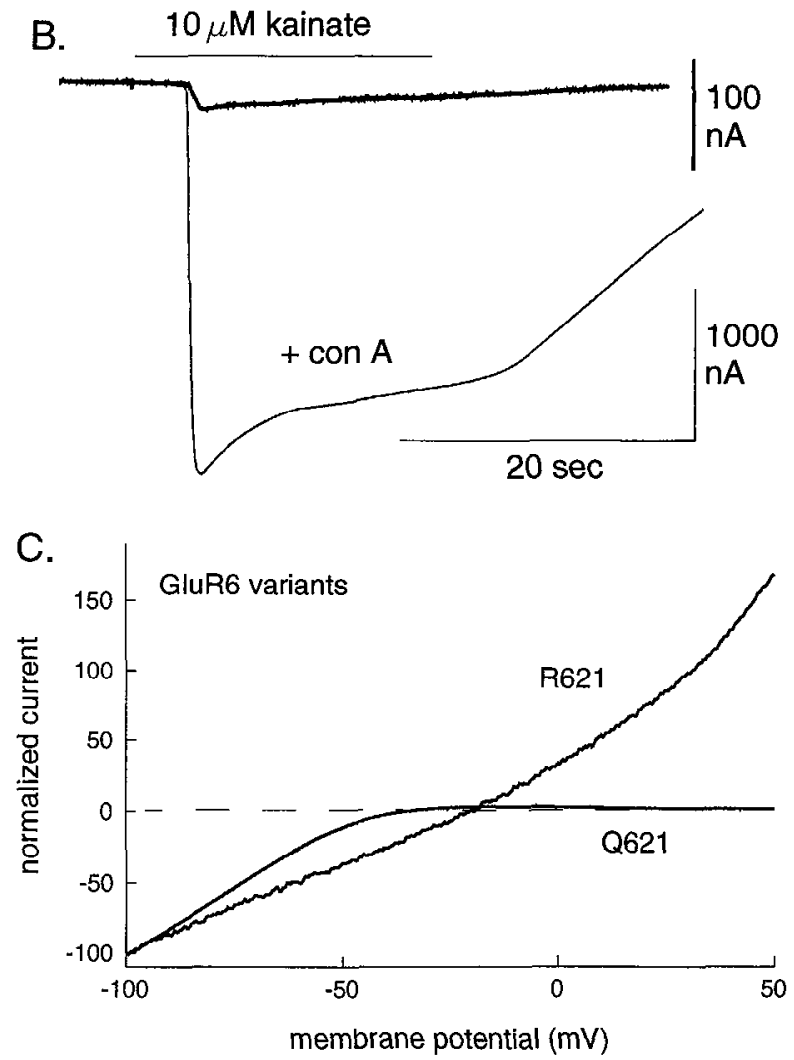

Figure 1. Properties of GluR6 variants at the $\mathrm{Q} / \mathrm{R}$ site. $A$, Sequence of GluR6 in the vicinity of the $\mathrm{Q} / \mathrm{R}$ site. $B$, Potentiation of kainate responses in GluR6(Q621) following exposure to $10 \mu \mathrm{M}$ concanavalin A. Holding potential, $-100 \mathrm{mV}$. $C, I-V$ relation for an oocyte expressing GluR6(R621) and for an oocyte expressing GluR6(Q621). Currents were normalized to those measured at $-100 \mathrm{mV}$.

approach was to change the size or charge of residues at the $Q$ / $\mathrm{K}$ site. The second was to examine the effects of repositioning the positively charged arginine to nearby sites. A third series of cxperiments tested whether mutation of the aspartate residue at position 616 can also effect the channel properties. The rationale for this choice was that this negatively charged residue is close enough to the arginine at 612 that they might form a salt bridge. If so, then removal of the residue that interacts specifically with the arginine should also alter the channel properties. The final series of experiments was based on the idea that homologous residues in glutamate receptor and nicotinic receptor channels may have similar functions. We therefore tested whether conversion of serine residues to alanine, which in the nicotinic $\mathrm{ACh}$ receptor ( $\mathrm{AAChR}$ ) channel reduces outward rectification (Leonard et al., 1988), has a similar effect in GluR3 channels. The mutations of GluR3 studied here are indicated in Figure 2.

\section{The arginine location influences rectification}

To determine the positional dependence of the arginine effect on the shape of the $I-V$ relation, five amino acids at or near the $\mathrm{Q} / \mathrm{R}$ site of GluR3 were replaced in turn by arginine. Replacement of the glycine four residues away [GluR3(G608R)] produced functionally detectable homomeric receptors in 13 of 24

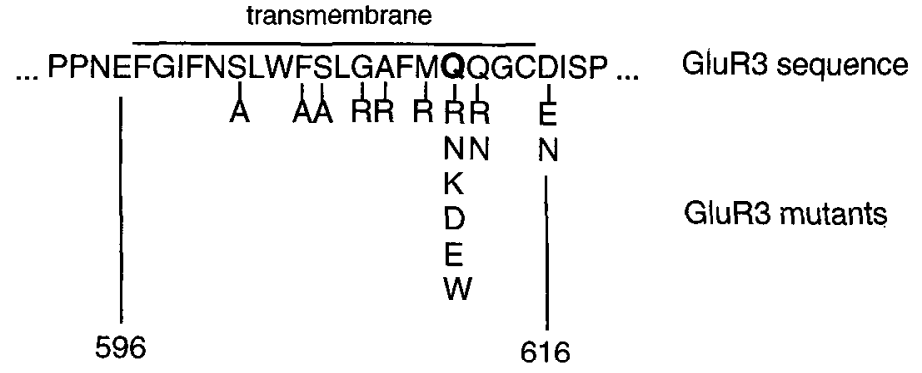

Figure 2. The amino acid mutations constructed for this study are indicated below the GluR3 sequence.

cells. The currents evoked by kainate were very small $(7 \pm 1$ $\mathrm{nA} ; n=13$ ) but displayed a nearly linear $I-V$ relation (Fig. $3 A$ ). In both of these properties, this mutant was similar to GluR2 or GluR3(Q612R). Replacement of the adjacent methionine or glutamine or the alanine three residues away from the $Q / R$ site with arginine $[($ GluR3(M611R), GluR3(Q613R), and (GluR3(A609R)] produced receptors that were inactive alone. Thus, introducing an arginine into any of a number of positions near the $Q / R$ site is sufficient to abolish the ability of homomeric receptors to carry large currents.

Each of the arginine-containing mutants gave a different result when coexpressed with GluR 1. Coexpression of GluR3(M611R) or GluR3(A609R) with GluR1 produced much smaller kainateevoked currents ( $0 \mathrm{nA}, n=15$, and $8 \pm 3 \mathrm{nA}, n=5$, respectively) than when GluR 1 was expressed by itself $(628 \pm 124 \mathrm{nA} ; n=$ 47). These "killer" mutants appear to code for subunits that can coassemble with GluR1 into a nonfunctional complex. The inhibition of GluR 1-evoked current by these killer mutations was not the result of contamination of the mRNA preparations with RNases or other toxic elements, since when oocytes were coinjected with mRNAs encoding GluR1, a killer, and the $\alpha_{3}$ and $\beta_{4}$ subunits of nAChRs, the nicotinic ACh responses were comparable to these evoked in oocytes injected with only $\alpha_{3}$ and $\beta_{4}$.

In contrast, when coexpressed with GluR1, both GluR3(Q613R) and GluR3(G608R) produced inward currents comparable in amplitude to when GluR1 was expressed with GluR3. Examination of the $I-V$ relation showed that both of these combinations allowed some outward current flow, although not as much as when GluR1 was coexpressed with GluR3(Q612R) (Fig. 3B,C).

Comparison of the rectification ratios of the arginine-containing mutants when they were coexpressed with GluR1 (Fig. $3 D$ ) allowed us to quantify the effect of placing an arginine at different positions. Although insertion of an arginine at some nearby positions allowed the flow of outward current, the $Q / R$ site was the most effective position for eliciting outward current flow.

By constructing chimeras of GluR1, GluR2, and GluR3, we have previously shown that the domain responsible for divalent ion permeability and outward current lies between amino acids 354 and 776 in GluR3 (Hume et al,, 1991). Within this large region, there is only one position other than the $Q / R$ site that contains a neutral residue (glutamine) in GluR 1 and GluR3 but a positively charged residue (lysine) in GluR2. As an additional test for specificity, we converted the glutamine to a lysine at this position in GluR3. This GluR3 mutant, Q343K, behaved identically to the parent GluR3, further suggesting the importance of the position of the positive charge. 
A.

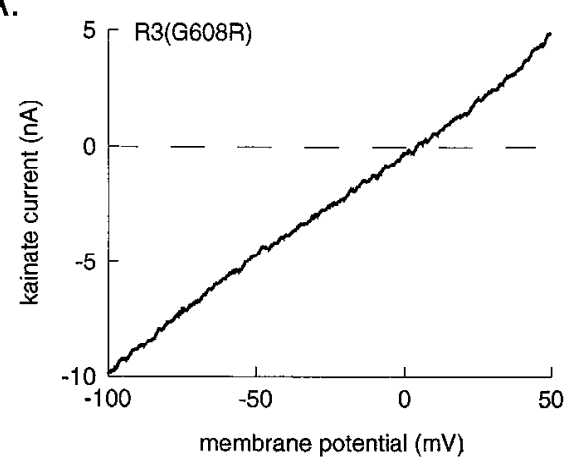

C.

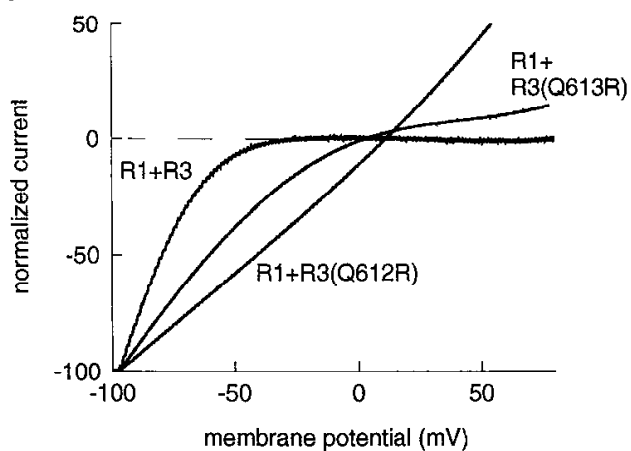

B.

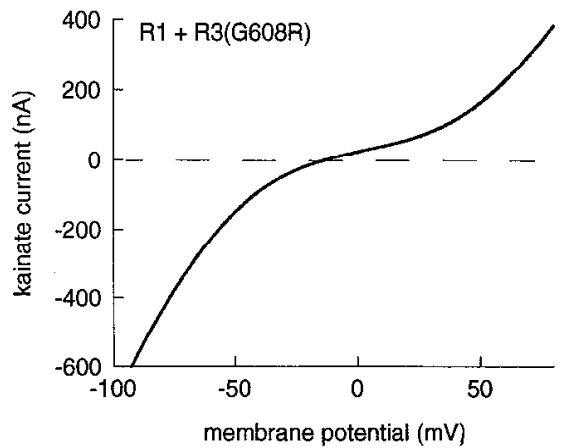

D.

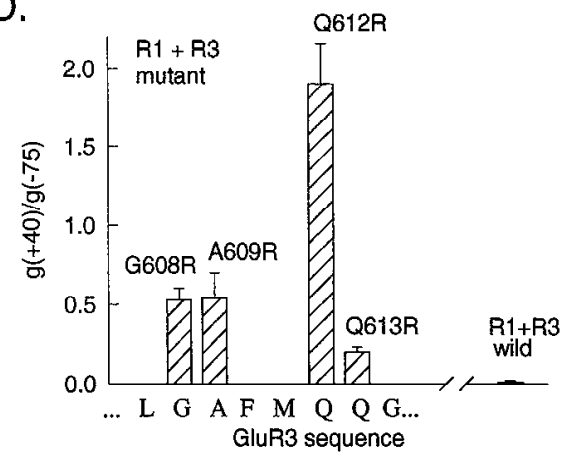

Figure 3. The effect of position of the arginine on rectification in the $I-V$ relation. $A, I-V$ relation of an oocyte expressing GluR3(G608R). $B, I-V$ relation of an oocyte coexpressing GluR 1 and GluR3(G608R). The RNAs were injected at a molar ratio of 1 GluR 1 to 5 GluR3(G608R). $C, I-V$ relations for cclls cocxpressing GluR1+GluR3, GluR1 + GluR3(Q612R), and GluR1 + GluR3(Q613R). The response amplitudes were normalized by dividing by the current amplitude measured at -100 $\mathrm{mV}$. In all three cases, the RNAs were injected at a GluR1:mutant ratio of 1:5. $D$, Rectification index for oocytes coexpressing GluR I and a second subunit. For each of a series of cells, the slope conductance of the $I-V$ relation was measured at $+40 \mathrm{mV}$ and $-75 \mathrm{mV}$ and the ratio of these conductances was calculated. The bars indicate the mean rectification index, and the error bars, the SEM. Seven or more cells were studied for each combination.

\section{Ability to pass outward current does not imply low divalent cation permeability}

The permeability to divalent cations can be assessed by switching cells from a solution in which the dominant cation is $\mathrm{Na}$ to one in which the dominant cation is $\mathrm{Ba}$. For combinations of subunits with low divalent cation permeability, the reversal potential becomes much more negative in the high divalent solution, while for combinations with high divalent permeability currents reverse at more positive potentials. All combinations of GluR1, GluR2, and GluR3 produce receptors with either strong inward rectification and high Ba permeability, or modest outward rectification and low Ba permeability (Hollmann et al., 1991; Hume et al., 1991; Burnashev et al., 1992). In two mutations of GluR3, however, these properties could be uncoupled.

Replacing the glutamine at the $\mathrm{Q} / \mathrm{R}$ site with asparagine reduces the length of the side chain by one carbon without changing its polarity. Kainate currents in GluR3(Q612N) receptors exhibited a linear or outwardly rectifying $I-V$ relation in $\mathrm{Na}-$ containing medium (Fig. $4 A$, thin line) rather than the inwardly rectifying $I-V$ relation characteristic of the GluR3 parent. However, although this construct could conduct outward current, it possessed high Ba permeability, since replacement of $90 \mathrm{mM}$ $\mathrm{NaCl}$ with $60 \mathrm{mM} \mathrm{BaCl}_{2}$ caused a shift to the right of the reversal potential (Fig. $4 A$, thick line). Similar to the other subunit combinations that are permeable to divalent cations, substitution of $\mathrm{Ba}$ for $\mathrm{Na}$ also caused a reduction in the magnitude of the inward current at all membrane potentials. Preservation of high divalent ion permeability in mutant receptors displaying outwardly rectifying $I-V$ relations has also recently been shown by others (Burnashev et al., 1992; Curutchet et al., 1992).

The negatively charged aspartate at position 616 of GluR 3 is close enough to the arginine at the $\mathrm{Q} / \mathrm{R}$ site (position 612) that they could potentially form a salt bridge. If so, the charge and/ or the size of the aspartate might be critical for function. Increasing the size of this residue by one carbon, by substitution of glutamate for aspartate at this position [GluR3(D616E)], produced inwardly rectifying currents that did not differ from GluR3 (Fig. 4B). In contrast, substitution of asparagine for aspartate at this position, which eliminates the negative charge without appreciably altering the size of the side chain, caused a clear change in the $I-V$ relation. This mutant, GluR3(D616N), displayed a sigmoidal $I-V$ relation, with both inward and outward rectification (Fig. 4B). Although this mutant receptor could pass large outward currents in response to kainate, its permeability to divalent cations was nevertheless high as judged by the large shift to the right in the kainate reversal potential when Ba replaced $\mathrm{Na}$ as the principal charge carrier (Fig. 4C).

The results from a series of cells injected with these mutants are summarized in Figure $4 D$. Substitution of asparagine for either D616 or Q612 resulted in homomeric receptors that could pass large outward currents (rectification index, >1). However, unlike the combinations of GluR 1 + GluR2 and GluR3 + GluR2, in which the ability to pass outward current is associated with low Ba permeability, in these mutants Ba permeability was high, like that of the parent GluR3. No mutants were identified that showed strong inward rectification and very low Ba permeability. These results together demonstrate that ability to pass outward current and low Ba permeability are not invariably linked, so they are likely to be controlled by separate mechanisms. Non-NMDA receptors are permeable to divalent cations in type 2 astrocytes (Pruss et al., 1991) and retinal bipolar cells of salamander (Gilbertson et al., 1991), yet both cell types display a nearly linear or outwardly rectifying $I-V$ relation to kainate (Gilbertson et al., 1991; Wyllie et al., 1991). In neurons or astrocytes, however, whether this combination of properties is due to a mixture of receptor subtypes within individual cells, or to a single receptor type, has not been distinguished. Our 
Figure 4. Separation of ability to pass outward current and low Ba permeability. $A, I-V$ relation for an oocyte expressing GluR3(Q612N), in high-Na (thin line, left current scale) and highBa (thick line, right current scale) solutions. $B, I-V$ relation in the standard solution for an oocyte expressing GluR3(D616E) and an oocyte expressing GluR3(D616N). The response amplitudes were normalized by dividing by the current amplitude at $-100 \mathrm{mV}$. $C, I-V$ relations for an oocyte expressing GluR3(D616N), in high-Na (thin line, left current scale) and high-Ba (thick line, right current scale). $D$, Rectification index (ratio of kainate-evoked conductance measured at $+40 \mathrm{mV}$ and -75 $\mathrm{mV}$ ) in standard $\mathrm{Na}$ solution (open squares) and reversal potential in high$\mathrm{Na}$ (open circles) and high-Ba (solid circles) solutions for a series of oocytes expressing the indicated subunits $(n>$ 5 cells for each measurement). The error bars indicate the SEM.
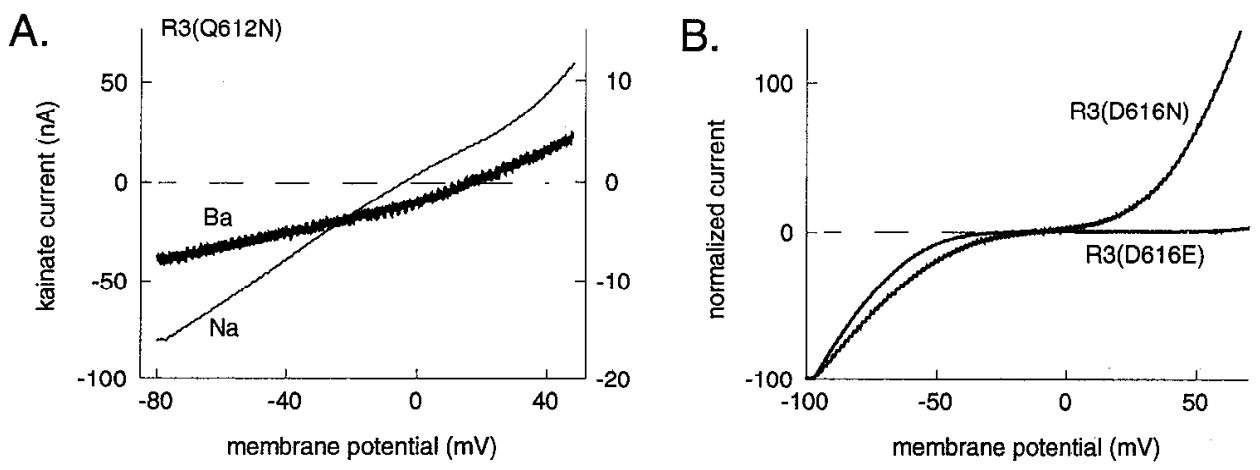

C.

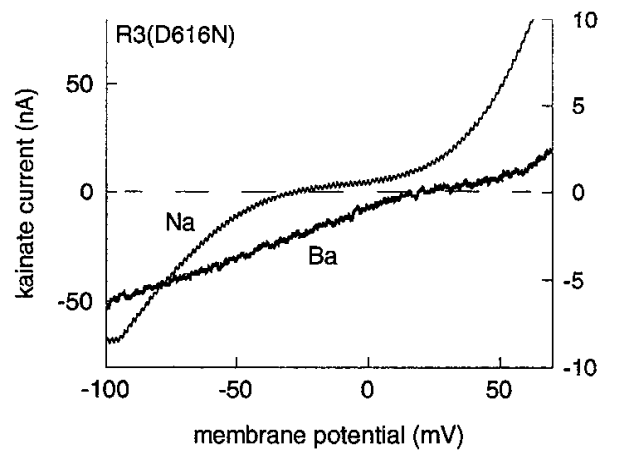

D.

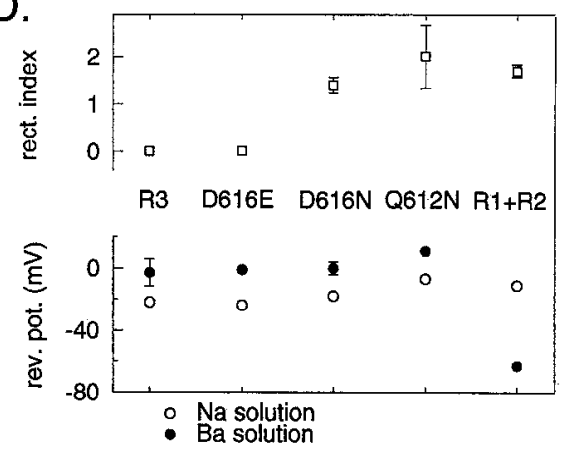

results with mutant GluR3 receptors (D616N and Q612N) demonstrate that both properties can reside in a homomeric receptor (see also Curutchet et al., 1992).

When GluR1 or GluR3 subunits coassemble with a subunit containing an arginine at the $Q / R$ site [GluR2 or GluR3(Q612R)], the channels formed have a low Ba permeability. GluR2 also suppressed Ba permeability when coassembled with the mutant subunits GluR3(Q612N) and GluR3(D616N). When oocytes coexpressing GluR2 and GluR3(Q612N) were exposed to kainate, the reversal potential measured in $\mathrm{Ba}$ was shifted $-40 \pm$ $4.2 \mathrm{mV}(n=5)$ from the reversal potential in Na solution. For oocytes expressing GluR2+GluR3(D616N), the shift was -43 $\pm 1.7 \mathrm{mV}(n=8)$. Thus, although these mutants differ from their parent in the ability to pass outward current, they may not differ in how divalent permeability is regulated.

\section{Size as well as charge at position 612 influences barium permeability}

The amino group of lysine and the guanidino group of arginine both carry a positive charge, but lysine has a somewhat smaller side chain. Coexpression of GluR 1 with the lysine-containing GluR3 mutant Q612K, like the arginine mutant Q612R, produced receptors with outwardly rectifying kainate currents in Na-containing medium (Fig. 5A). When $\mathrm{Ba}$ replaced $\mathrm{Na}$ as the major charge carrier, however, the shift in kainate reversal potential was smaller for lysine-containing than for arginine-containing mutants (Fig. $5 A, B$ ). Assuming no difference in monovalent permeability in the two mutants, $P_{\mathrm{Ba}} / P_{\text {monovalent }}$ was about 0.05 for GluR 1 + GluR3(Q612R) channels but was increased to 0.20 in GluR $1+$ GluR3(Q612K) channels. A potential alternative explanation, that $P_{\mathrm{K}} / P_{\mathrm{Na}}$ is lower for the $\mathrm{Q} 612 \mathrm{~K}$ mutant than the Q612R mutant, cannot account quantitatively for the results. If the $\mathrm{Q} 612 \mathrm{~K}$ mutant were impermeable to $\mathrm{Ba}^{2+}$, the reversal potential of $-35 \mathrm{mV}$ in barium solution predicts $P_{\mathrm{K}} /$ $P_{\mathrm{Na}}=0.2$. However, in $\mathrm{Na}$ solution the reversal potential would then be $+30 \mathrm{mV}$ rather than the observed $-4 \pm 1.4 \mathrm{mV}(n=$ 9). Thus, these results suggest that the size of the positively charged side chain, or the distributed electron cloud in the guanidino head group of arginine, is an important determinant of barium permeability.

Several other GluR3 mutants were constructed in attempts to modify size or charge at or near the $Q / R$ site. Negatively charged Q612D and Q612E, the large substitution Q612W, and Q613N were all inactive alone. When the Q612 mutants were coexpressed with GluR1, the GluR1 responses were substantially attenuated. For example, in one experiment $300 \mu \mathrm{M}$ kainate evoked $694 \pm 137 \mathrm{nA}$ of current $(n=11)$ in oocytes expressing GluR $1+$ GluR 3 subunits, but only $95 \pm 40 \mathrm{nA}(n=$ 11) in oocytes injected with GluR1+GluR3(Q612D). The small residual (inwardly rectifying) currents in the latter set of cells may reflect activity of homomeric GluRl receptors or greatly diminished current flow through heteromeric channels in which aspartate replaces glutamine at some $Q / R$ sites.

Because of a possible homology with important sites in nicotinic receptor channels (see Discussion), two serines and the adjacent phenylalanine in GluR3 were converted in turn to alanine (Fig. 2). Both serine mutants, S602A and S606A, were similar to GluR3 with respect to rectification and $\mathrm{Ba}$ permeability, however, whether expressed alone or with GluR2. Thus, these experiments have not demonstrated a role for the serine residues in ion permeation through glutamate receptor channels. Conversion of a nearby phenylalanine to alanine (F605A) produced another "killer" GluR3 mutant, indicating that residues in this region can have a major effect on the structure of the receptor.

\section{Discussion}

The results presented here confirm that the $Q / R$ site in the GluR1-GluR4 family of non-NMDA glutamate receptors plays an important role in ion permeation (Hume et al., 1991; Ver- 


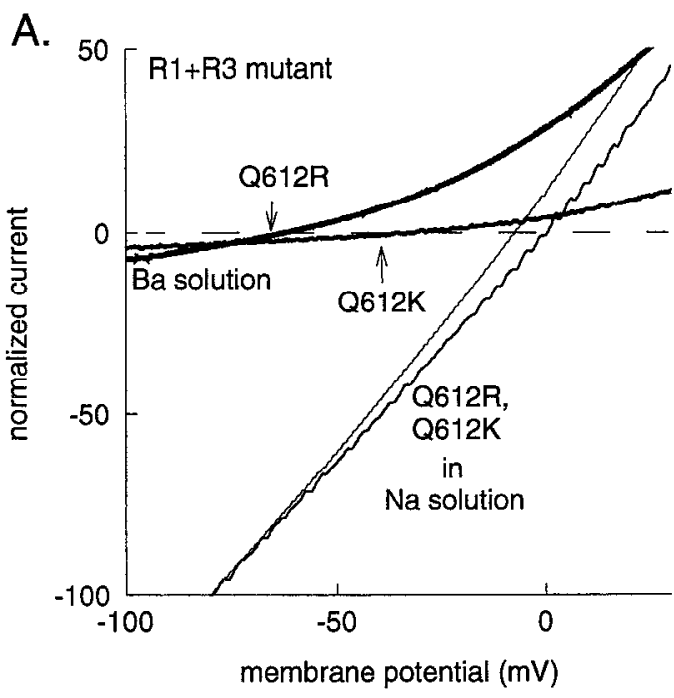

doorn et al., 1991; Burnashev et al., 1992), and extend this finding to the GluR5-GluR7 family. Four new observations support the suggestion that the $Q / R$ site is in or near the path of permeating ions. First, $P_{\mathrm{Ba}} / P_{\text {monovalent }}$ was four times larger when lysine resided in the $Q / R$ site than when arginine was present (Fig. 5). This result might be explained by the difference in size (lysine is smaller than arginine), or differences in chemical reactivity of the positive charge in the two amino acids (guanidino in arginine, amino in lysine). Second, other substitutions at the $Q / R$ site also influenced ion permeation. Reducing the length of the polar side chain of glutamine by introducing an asparagine at the $Q / R$ site allowed outward as well as inward current (Fig. 4A), whereas increasing the size of the side chain (tryptophan substitution) or inserting a negative charge (glutamate and aspartate substitution) abolished all currents. Third, the optimum location for arginine was at the $Q / R$ site itself (Fig. 3), ruling out the possibility that the simple presence of a positive charge in this region results in outward rectification. Fourth, mutation of a second position four residues away from the $Q$ / R site, GluR3(D616N), also altered the ability to carry outward current (Fig. $4 B$ ). In contrast, removal of the hydroxyl group from either serine, 6 or 10 residues on the other side of the $Q$ / $\mathrm{R}$ site, had no consistent effect on rectification or Ba permeability.

These results are consistent with the idea that the amino acid side chain at the $Q / R$ site interacts with permeating cations, especially divalents. We emphasize, however, that the mutagenesis approach can provide only indirect evidence that the $Q$ / $\mathrm{R}$ site lies within the channel. Without independent evidence that the $Q / R$ region is actually in the channel, it remains possible that the effects observed are due to conformational changes in the channel structure rather than a more direct chemical interaction with permeating ions.

\section{Relationship between channel structure and rectification}

The structural basis for inward rectification in glutamate receptors lacking GluR2 remains unclear. Although rectification and high $\mathrm{Ba}$ permeability go together in the naturally occurring receptors, these properties were uncoupled in two mutants (Fig. 4). Comparison of the GluR3 sequence with the sequence of $\mathrm{nACh}$ receptors is potentially informative, since neuronal nicotinic receptors show both inward rectification (Couturier et al., 1990; Mathie et al., 1990; Fieber and Adams, 1991; Sands and Barish, 1992) and high divalent permeability (Fieber and Adams, 1991; Sands and Barish, 1991). The second putative transmembrane domain (TM2) of the nicotinic receptor has been proposed to donate side chains to the lining of the ion channcl wall (scc Unwin, 1989, for review). The TM2 sequence of the rat neuronal $\alpha_{2}$ nAChR subunit is shown in Figure 6 . Several individual amino acids within TM2 that play important roles in ion permeation in nicotinic receptor channels are in boldface. The leftmost glutamate in the AChR sequence influences the rate of ion permeation and channel block by internal $\mathrm{Mg}$ in Torpedo AChR channels (Imoto et al., 1988). The next glutamate in the sequence, which forms the intermediate ring of negative charge near the cytoplasmic mouth of the channel (Imoto et al., 1988), together with a nearby threonine constitutes part of the selectivity filter of Torpedo AChR channels (Konno et al., 1991; Villarroel et al., 1991). The serine residues near the center of this transmembrane domain are thought to donate hydroxyl groups to the channel wall since substitution of alanines at these sites in mouse $\mathrm{nAChR}$ reduces outward conductance selectively and decreases the dwell time of the open channcl blocker QX-222 (Lconard et al., 1988; Charnet et al., 1990). Mutations of the marked leucine, which is highly conserved in ligand-gated ion channels, modify several aspects of permeation and gating in neuronal $\alpha_{7}$ AChR (Revah et al., 1991).

The topology of glutamate receptors is not known, although models have been proposed that involve three closely spaced transmembrane regions plus a fourth near the C-terminus. In one model (Hollmann et al., 1989), the sequence of GluR3 in which the $Q / R$ site resides lies in an extracellular loop. In another model this sequence serves as the second transmembranespanning region, and thus crosses the membrane from the cytoplasmic to extracellular side (Keinanen et al., 1990; Nakanishi et al., 1990; Sakimura et al., 1990). This orientation is shown in Figure $6 A$, with the critical $\mathrm{Q} / \mathrm{R}$ site in boldface and the transmembrane topology indicated to the right. It is possible from the hydropathy plots, however, to postulate that this sequcncc forms instcad the third transmembrane domain, in which case it crosses the membrane in the extracellular-to-cytoplasmic direction. This alternative orientation is shown in Figure $6 B$. The similarity with the AChR sequence is strong in either orientation. If this GluR3 sequence is TM3, then the $Q / R$ site in glutamate receptors is near the position of residues known to contribute to the selectivity filter of AChR channels. 
A. nAChR (TM2) GluR3 (If TM2)

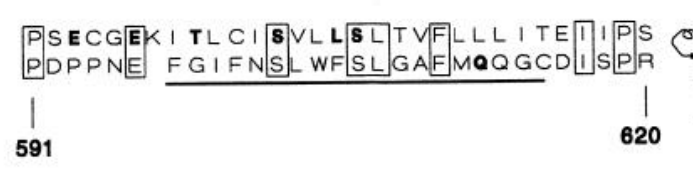

B.

กAChR (TM2) GluR3 (II TM3)

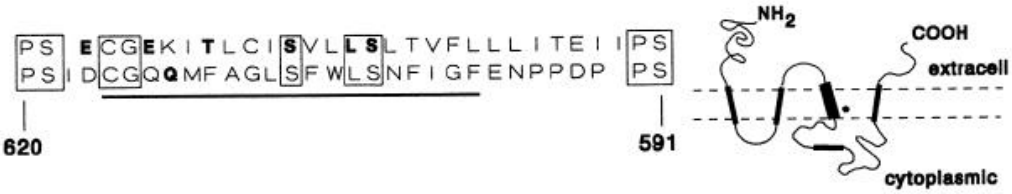

Figure 6. Comparison of sequence of GluR3 near the Q/R site with the TM2 sequence of the $\alpha$, subunit of rat neuronal nAChR channels (Wada et al., 1988). Amino acids in the TM2 sequence that are known to have effects on ion permeation (see Discussion) are indicated in boldface, as is the $\mathrm{Q} / \mathrm{R}$ site of GluR3. The putative transmembrane segments are indicated by underlining, and identical residues are boxed. Two alternative orientations of the GluR3 sequence are shown. A, Alignment of sequences if the GluR3 domain is TM2. The sequences are aligned so that extracellular to intracellular goes from left to right. The schematic to the right indicates possible transmembrane domains by the solid boxed regions. The position of the $\mathrm{Q} / \mathrm{R}$ site is indicated by the asterisk next to the largest boxed region. B, Sequence alignment if the GluR3 domain shown forms TM3. In this case, the GluR3 sequence traverses the membrane in the opposite direction than does TM2 of the nAChR. Another transmembrane topology that is consistent with the hydropathy plots is that the sequence containing the $Q / R$ site is the third of five membrane-spanning domains.

The proposed mechanism for rectification in the neuronal nicotinic receptor also suggests, by analogy, that the $Q / R$ site may be near the intracellular side of the membrane. Rectification in the neuronal nicotinic receptor appears to be due to a combination of rapid voltage-dependent channel gating and channel block by internal Mg (Mathie et al., 1990; Sands and Barish, 1992). Since the negatively charged amino acids forming the cytoplasmic rings in Torpedo AChR are important for internal $\mathrm{Mg}$ block (Imoto et al., 1988), it seems possible that the free carboxyl group of D616 may contribute to an internal cation binding site that causes inward rectification. If this is true, the arginine found naturally in GluR2 might prevent block by forming a salt bridge that neutralizes the negative charge of the aspartate at position 616. It follows that removal of the negative charge at this site in GluR3 should allow outward current, which we observed (Fig. $4 B$ ). To preserve the analogy with nicotinic receptors, however, D616 must be located on the intracellular side of the membrane, which implies that the sequence studied here is TM3 rather than TM2 as postulated (Keinanan et al., 1990; Nakanishi et al., 1990; Sakimura et al., 1990). Further evaluation of this suggestion requires more direct determination of the sidedness and topology of this region in glutamate receptors, and identification of the putative blocking ion.

\section{Comparison of divalent permeability of different receptors}

Calculations based on the constant field equation indicate that the $20 \mathrm{mV}$ positive shift in reversal potential that is characteristic of the Ba-permeable combinations [e.g., GluR1, GluR1 + GluR3, GluR3(D616N), GluR3(Q612N)] implies that $P_{\mathrm{Ba}} / P_{\text {monovalent }}$ is about 3 . In contrast, for combinations in which one or more of the subunits contain an arginine or lysine at the $\mathrm{Q} / \mathrm{R}$ site, the -30 to $-50 \mathrm{mV}$ negative shift corresponds to a $P_{\mathrm{Ba}} / P_{\text {monovalent }}$ of less than 0.2 . This calculation does not take charge screening into account (see Materials and Methods) but is useful for comparison with values similarly calculated for other receptors. For example, $P_{\text {divalent }} / P_{\text {monovalent }}=5$ for inwardly rectifying (type II) kainate receptors on hippocampal neurons in culture (Iino et al., 1990), <0.2 for nonrectifying (type I) kainate receptors (Mayer and Westbrook, 1987; Iino et al., 1990), 8-10 for NMDA receptors (Mayer and Westbrook, 1987), and 1-2 for neuronal nicotinic receptors in PC12 cells (Sands and
Barish, 1991). Thus, calcium influx through neuronal nicotinic and some glutamate receptors may serve roles previously relegated only to the NMDA receptors.

In summary, the $\mathrm{Q} / \mathrm{R}$ site of non-NMDA glutamate receptors has been shown to control the degree of divalent ion permeation and rectification in both families of non-NMDA glutamate receptors. These results are consistent with the notion that the general architecture of the channel region of glutamate and nicotinic receptors may be similar (Unwin, 1989). Now that the amino acid sequence of one NMDA receptor subunit is known (Moriyoshi et al., 1991), it is interesting to consider whether similar rules apply to permeation and block by divalent cations in NMDA receptors. The NMDA receptor sequence has an asparagine at the position that appears to be homologous to the Q/R site in the GluR1-GluR4 and GluR5-GluR7 families. Interestingly, when we introduced an asparagine into this site in GluR3 (see also Burnashev et al., 1992), the channels exhibited a nearly linear $I-V$ relation and high barium permeability (Fig. $4 A$ ), both characteristics of NMDA receptor channels. However, NMDA channels only carry substantial inward current at negative potentials in the absence of extracellular $\mathrm{Mg}$. Our experiments were carried out in the presence of $1.7 \mathrm{mM}$ extracellular $\mathrm{Mg}$, a concentration that would have nearly completely suppressed inward current through the NMDA receptor channel in oocytes (Kleckner and Dingledine, 1991). It is little surprise that our findings with this mutant AMPA receptor subunit cannot be used to explain all the typical features of the NMDA receptor channel. Nevertheless, the substantial homology between the NMDA-R1 subunit and GluR1-GluR7 in this region suggests that the channel domain for all glutamate receptors may be similar.

\section{References}

Ascher P, Nowak L (1988) The role of divalent cations in the $\mathrm{N}$ methyl-D-aspartate responses of mouse central neurones in culture. J Physiol (Lond) 399:247-266.

Barish ME (1983) A transient calcium-dependent chloride current in the immature Xenopus oocyte. J Physiol (Lond) 342:309-325.

Bettler B, Boulter J, Hermans-Borgmeyer I, O'Shea-Greenfield A, Deneris ES, Moll C, Borgmeyer U, Hollmann M, Heinemann S (1990) Cloning of a novel glutamate receptor subunit, GluR5: expression in the nervous system during development. Neuron 5:583-595. 
Bettler B, Egebjerg J, Sharma G, Pecht G, Hermans-Borgmeyer I, Moll C, Stevens CF, Heinemann S (1992) Cloning of a new glutamate receptor: a low-affinity kainate binding subunit. Neuron 8:257-265.

Boton R, Dascal N, Gillo B, Lass Y (1989) Two calcium-activated chloride conductances in Xenopus laevis oocytes permeabilized with the ionophore A23187. J Physiol (Lond) 408:511-534.

Boulter J, Hollmann M, O'Shea-Greenfield A, Hartley M, Deneris E, Maron C, Heinemann S (1990) Molecular cloning and functional expression of glutamate receptor subunit genes. Science 249:10331037.

Burnashev N, Monyer H, Seeburg PH, Sakmann B (1992) Divalent ion permeability of AMPA receptor channels is dominated by the edited form of a single subunit. Neuron 8:189-198.

Charnet P, Labarca C, Leonard RJ, Vogelaar NJ, Czyzyk L, Gouin A, Davidson N, Lester HA (1990) An open channel blocker interacts with adjacent turns of $\alpha$-helices in the nicotinic acetylcholine receptor. Neuron 4:87-95.

Couturier S, Erkman L, Valera S, Rungger D, Bertrand S, Boulter J, Ballivet M, Bertrand D (1990) $\alpha_{5}, \alpha_{3}$, and non- $\alpha_{3}$. Three clustered avian genes encoding neuronal nicotinic acetylcholine receptor-related subunits. J Biol Chem 265:17650-17657.

Curutchet P, Bochet P, Prado de Carvalho L, Lambolez B, Stinnakre J, Rossier J (1992) In the GluR I glutamate receptor subunit a glutamine to histidine point mutation suppresses inward rectification but not calcium permeability. Biochem Biophys Res Commun 182: 1089-1093.

Dascal N, Snutch TP, Lubbert H, Davidson N, Lester HA (1986) Expression and modulation of voltage-gated calcium channels after RNA injection in Xenopus oocytcs. Science 231:1147-1150.

Egebjerg J, Bettler B, Hermans-Borgmeyer I, Heinemann S (1991) Cloning of a cDNA for a glutamate receptor subunit activated by kainate but not AMPA. Nature 351:745-748.

Fieber LA, Adams DJ (1991) Acetylcholine-evoked currents in cultured neurones dissociated from rat parasympathetic cardiac ganglia. J Physiol (Lond) 434:215-237.

Gilbertson TA, Scobey R, Wilson M (1991) Permeation of calcium ions through non-NMDA glutamate channels in retinal bipolar cells. Science 251:1613-1615.

Glaum SR, Holzwarth JA, Miller RJ (1990) Glutamate receptors activate $\mathrm{Ca}^{2+}$ mobilization and $\mathrm{Ca}^{2+}$ influx into astrocytes. Proc Natl Acad Sci USA 87:3454-3458.

Hollmann M, O'Shea-Greenfield A, Rogers SW, Heinemann S (1989) Cloning by functional expression of a member of the glutamate receptor family. Nature 342:643-648.

Hollmann M, Hartley M, Heinemann S (1991) $\mathrm{Ca}^{2+}$ permeability of KA-AMPA-gated glutamate receptor channels depends on subunit composition. Science 252:851-853.

Hume RI, Dingledine R, Heinemann S (1991) Identification of a site in glutamate receptor subunits that controls calcium permeability. Science 253:1028-1031.

Iino M, Ozawa S, Tsuzuki K (1990) Permeation of calcium through excitatory amino acid receptor channels in cultured rat hippocampal neurones. J Physiol (Lond) 424:151-165.

Imoto K, Busch C, Sakmann B, Mishina M, Konno T, Nakai J, Bujo H, Mori Y, Fukuda K, Numa S (1988) Rings of negatively charged amino acids determine the acetylcholine receptor channel conductance. Nature 335:645-648.

Keinanen K, Wisden W, Sommer B, Werner P, Herb A, Verdoorn T, Sakmann B, Seeburg PH (1990) A family of AMPA-selective glutamate receptors. Science 249:556-560.

Kleckner NW, Dingledine R (1991) Regulation of hippocampal NMDA receptors by magnesium and glycine during development. Mol Brain Res 11:151-159.

Konno T, Busch C, Von Kitzing E, Imoto K, Wang F, Nakai J, Mishina
M, Numa S, Sakmann B (1991) Rings of anionic amino acids as structural determinants of ion selectivity in the acetylcholine receptor channel. Proc R Soc Lond [Biol] 244:69-79.

Leonard RJ, Labarca CG, Charnet P, Davidson N, Lester HA (1988) Evidence that the M2 membrane-spanning region lines the ion channel pore of the nicotinic receptor. Science 242:1578-1581.

Lewis CA (1979) Ion-concentration dependence of the reversal potential and the single channel conductance of ion channels at the frog neuromuscular junction. J Physiol (Lond) 286:417-445.

Mathie A, Colquhoun D, Cull-Candy SG (1990) Rectification of currents activated by nicotinic acetylcholine receptors in rat sympathetic ganglion neurones. J Physiol (I ond) 427:625-655.

Mayer ML, Westbrook GL (1987) Permeation and block of $N$-methylD-aspartic acid receptor channels by divalent cations in mouse cultured central neurones. J Physiol (Lond) 394:501-527.

Miledi R, Parker I (1984) Choride current induced by injection of calcium into Xenopus oocytes. J Physiol (Lond) 357:173-183.

Moriyoshi K, Masu M, Ishii T, Shigemolo R, Mizuno N, Nakanishi S (1991) Molecular cloning and characterization of the rat NMDA receptor. Nature 354:31-37.

Murphy SN, Thayer SA, Miller RJ (1987) The effects of excitatory amino acids on intracellular calcium in single mouse striatal neurons in vitro. J Neurosci 7:4145-4158.

Nakanishi N, Shneider NA, Axel R (1990) A family of glutamate receptor genes: evidence for the formation of heteromultimeric receptors with distinct channel properties. Neuron 5:569-581.

Pruss RM, Akeson RL, Racke MM, Wilburn JL (1991) Agonist-activated cobalt uptake identifies divalent cation-permeable kainate reccptors on ncurons and glial cells. Neuron 7:509-518.

Revah F, Bertrand D, Galzi J-L, Devillers-Thiery A, Mulle C, Hussy N, Bertrand S, Ballivet M, Changeux J-P (1991) Mutations in the channel domain alter desensitization of a neuronal nicotinic receptor. Nature 353:846-849.

Sakimura K, Bujo J, Kushiya E, Araki K, Yamazaki M, Yamazaki M, Meguro H, Warashina A, Numa S, Mishina M (1990) Functional expression from cloned cDNAs of glutamate receptor species responsive to kainate and quisqualate. FEBS Lett 272:73-80.

Sands SB, Barish ME (1991) Calcium permeability of neuronal nicotinic acetylcholine receptor channels in PC12 cells. Brain Res 560: $38-42$.

Sands SB, Barish ME (1992) Neuronal nicotinic acetylcholine receptor currents in pheochromocytoma (PC12) cells: dual mechanisms of rectification. J Physiol (Lond), in press.

Sommer B, Kohler M, Sprengel R, Seeburg PH (1991) RNA editing in brain controls a determinant of ion flow in glutamate-gated channels. Cell 67:11-19.

Unwin N (1989) The structure of ion channels in membranes of excitable cells. Neuron 3:665-676.

Verdoorn TA, Burnashev N, Monyer H, Seeburg PH, Sakmann B (1991) Structural determinants of ion flow through recombinant glutamate receptor channels. Science 252:1715-1718.

Vieira J, Messing J (1987) Production of single-stranded plasmid DNA. Methods Enzymol 153:3-10.

Villarroel A, Herlitze S, Koenen M (1991) Location of a threonine residue in the $\alpha$-subunit M2 transmembrane segment that determines the ion flow through the acetylcholine receptor channel. Proc R Soc Lond [Biol] 243:69-74.

Wada K, Ballivet M, Boulter J, Connolly J, Wada E, Deneris ES, Swanson LW, Heinemann S, Patrick J (1988) Functional expression of a new pharmacological subtype of brain nicotinic acetylcholine receptor. Science 240:330-334.

Wyllie DJ, Mathie A, Symonds CJ, Cull-Candy SG (1991) Activation of glutamate receptors and glutamate uptake in identified macroglial cells in rat cerebellar cultures. J Physiol (Lond) 432:235-258. 